\title{
Outcome of Surgical Site Infection in General Surgical Practice in a District Hospital
}

\author{
A RAHMAN ${ }^{\mathrm{a}}$, FS JOTY $^{\mathrm{b}}$
}

\begin{abstract}
:
Background: Surgical site infection (SSI) can affect the surgical procedures in the peripheral hospital adversely and adequate data can help in the management of this unwanted complication.

Aim \& Objective: The study was conducted with the aim to identify the outcome of surgical site infection (SSI) in a secondary level district hospital.

Materials \& Methods: A total of 192 patients, underwent general surgical procedures in the 100-bedded district hospital, Shariatpur, Bangladesh from January to December, 2016. All were observed for development of SSI for a period of 30 days after their surgical procedure. SSI cases were identified according to National Healthcare Safety Network (CDC/NHSN) guideline and Southampton wound scoring system. Univariate and multivariate analysis was
\end{abstract}

\section{Introduction:}

Surgical site infection (SSI) is defined as infection occurring within 30 days (or within one year if implant is in place) after the operation at site of surgery or at any part of the body opened or manipulated during the procedure. ${ }^{1}$ It is classified into three categories; 1. Superficial incisional, 2. Deep incisional, and 3. Organ/ space SSI (Table 1). Despite advances in infection control practices, SSI remains a substantial burden over our healthcare system. In the USA, SSI is ranked third among all reported cases of inpatient nosocomial infections. ${ }^{2}$ SSI increases patients' morbidity, hospital stay and mortality, and ultimately can have serious economic consequences. It is the commonest healthcare associated infection (HAI) in low- and middle-income countries (LMIC) like Bangladesh and second most in Europe and USA. ${ }^{3}$ Incidence varies from region to region. In LMICs, the pooled incidence of SSI was 11.8 per 100

a. Dr. Ashrafur Rahman, Assistant Professor (Surgery), MS Phase B Resident (Surgical Oncology), National Institute of Cancer Research and Hospital (NICRH), Mohakhali, Dhaka.

b. Dr. Fahmida Sharmin Joty, Assistant Professor, CARe Medical College, Mohammadpur, Dhaka.

Address of Correspondence: Dr. Ashrafur Rahman, FCPS (Surgery), Assistant Professor (Surgery), MS Phase B Resident (Surgical Oncology), National Institute of Cancer Research and Hospital (NICRH), Mohakhali, Dhaka. Mailing Address - Industrial Plot - 9, Block - C, Tajmahal Road, Mohammadpur, Dhaka1207. Mobile: 01716048789, e-mail-romeo2113@gmail.com

Received: 14 Septe., 2019

Accepted: 20 March, 2021 done to identify significant risk factors for development of SSI.

Results: Overall incidence of SSI was $20.31 \%$. Significant risk factors for development of SSI were age, BMI, ASA grade, wound classification, diabetes, type of surgery, duration of surgery and perioperative transfusion $(p<0.05)$. Among them, BMI $(O R=1.434)$, diabetes $(O R=8.126)$, type of surgery (routine/emergency) $(O R=6.097)$, duration of surgery $(O R=1.023)$ and perioperative transfusion $(O R=2.130)$ were determined as independent risk factors on logistic regression.

Conclusion: SSI has a relatively high incidence in rural surgical practice. Identification and control of predictable risk factors would help to reduce the incidence of SSI.

Key-words: Surgical site infection, risk factor, general surgery

(J Bangladesh Coll Phys Surg 2021; 39: 171-177)

DOI: https://doi.org/10.3329/jbcps.v39i3.54158

surgical patients undergoing surgical procedures (range 1.2 to 23.6$){ }^{4}$ On the other hand it is much lower in developed countries like USA, France and Italy., 5,6,7 Several risk factors have been identified and make up the surgical infection risk index of the National Nosocomial Infection Surveillance System (NNIS) ${ }^{8}$ It is accepted worldwide that SSI is multifactorial and both intrinsic and extrinsic factors may act in unison to develop SSI. Also there is a common perception that SSI reflects poor quality of care. ${ }^{9}$ SSI prevention has therefore attracted considerable attention from surgeons and infection control physicians (ICPs) and also healthcare authorities in most developed countries.

Successful prevention strategy can only be formed and implemented when the exact incidence, causative factors and outcome are identified. Adequate data on this regard is not available from our healthcare services. This study was conducted in the surgery unit of a district hospital to identify the institutional incidence and attributable risk factors of SSI.

Materials and Methods:

Study design: A prospective observational study was conducted at the 100-bed District Hospital, Shariatpur. All consecutive patients aged 12 or more, who underwent general surgical procedures, both routine and emergency, in the general operating theater from January 2016 to December 2016 were included in the study. The operation theater complex had two operating rooms with standard 
facilities, one post-operative ward with four beds and trained staff to provide routine and 24-hour emergency service. There was no laparoscopy facility. For this study, ideal sample size was calculated using Cochran formula (95\% CI, $5 \%$ margin of error and standard incidence rate $15 \%)$. Calculated sample size $\left(n_{0}=\frac{z^{2} p(1-p)}{\rho^{2}} \approx 196\right)$ closely matched actual sample size which was 192. Both in-patient and day case surgeries were included. We excluded gynaecological and orthopedic surgeries (done in the same operating room on different weekdays). Procedures done in the OPD operating room or admitted SSI cases operated in other hospitals were excluded. Patients who had open wounds at the end of surgery as well as infected burn wounds were also excluded. Prophylactic antibiotics were administered in all cases except those done under local anesthesia, and was administered during induction. All patients received postoperative systemic and/or oral antibiotics. First check dressing was done in third to fifth postoperative day (POD) and subsequent dressings and stich removal were done according to wound status. Wounds were classified according to the Southampton Wound Scoring System. ${ }^{11}$ All patients were followed up for at least 30 days after surgery, either in the ward, surgical OPD or over telephone interview.

Data collection and statistical analysis: Demographic characteristics, clinical and pathological data, operative variables and postoperative outcome variables were collected in a preformed data collection sheet. All of the data were checked and analyzed with SPSS v20. Discrete variables were described as frequency and percentage, and continuous variables were described as mean and standard deviation. First, descriptive statistics, including count and percentage, were used to describe the

\section{Classification of Surgical Site Infection (SSI) (Summarized from "CDC/NHSN surveillance definition of health care-associated infection and criteria for specific types of infections in the acute care setting"; pg 313-14) ${ }^{10}$}

\section{Superficial incisional SSI}

Infection occurs within 30 days after the operative procedure and involves only skin and subcutaneous tissue of the incision and patient has at least 1 of the following:

a. purulent drainage

b. organisms isolated from an aseptically obtained culture of fluid or tissue

c. superficial incision deliberately opened by surgeon (culture positive or not cultured) and at least 1 of the following: pain or tenderness, localized swelling, redness, or heat (culture-negative finding does not meet this criterion)

d. diagnosis by the surgeon or attending physician

\section{Deep incisional SSI}

Infection occurs within 30 days after the operative procedure if no implant is left in place or within 1 year if implant is in place and the infection appears to be related to the operative procedure and involves deep soft tissues (eg, fascial and muscle layers) of the incision and patient has at least 1 of the following:

a. purulent drainage from the deep incision but not from the organ/space component of the surgical site

b. a deep incision spontaneously dehisces or is deliberately opened by a surgeon (culture-positive or not cultured) and the patient has at least 1 of the following signs or symptoms: fever $\left(>38^{\circ} \mathrm{C}\right)$, or localized pain or tenderness (culture-negative finding does not meet this criterion)

c. an abscess or other evidence of infection found on direct examination, during reoperation, or by histopathologic or radiologic examination

d. diagnosis by the surgeon or attending physician.

\section{Organ/Space SSI}

Infection occurs within 30 days after the operative procedure if no implant is left in place or within 1 year if implant is in place involving any part of the body, excluding the skin incision, fascia, or muscle layers, that is opened or manipulated during the operative procedure and patient has at least 1 of the following:

a. purulent drainage from a drain that is placed through a stab wound into the organ/space

b. organisms isolated from an aseptically obtained culture of fluid or tissue in the organ/space

c. an abscess or other evidence of infection involving the organ/space that is found on direct examination, during reoperation, or by histopathologic or radiologic examination

d. diagnosis by the surgeon or attending physician.

$\mathrm{CDC}=$ Center for Disease Control; NHSN $=$ National Healthcare safety Network 
demographic characteristics of the subjects. We used the Pearson and Wilcoxon univariable tests to guide the multivariable models for discrete and continuous variables, respectively. We used multivariable logistic regression models to identify preoperative and operative variables independently associated with SSI. The P-value for significance was set at 0.05 and the results are presented with an odds ratio $(\mathrm{OR})$ and a $95 \%$ confidence interval $(\mathrm{CI})$.

\section{Results:}

A total of 192 patients, 99 male (51.6\%) and 93 female (48.4\%), who underwent various general surgical procedures during January to December, 2016, were registered for this study. Among them 39 patients developed SSI (labelled as SSI+ group) giving an overall incidence rate of $20.31 \%$. The rest had no wound complication and were labelled as SSI- group. The $39 \mathrm{SSI}+$ cases comprised of 30 superficial incisional infections, seven deep incisional infections and two organ/space infections. Mean age of all patients was $34.62 \pm 9.32$ years (Range 12-60). Mean overall BMI was $23.47 \pm 1.97$ (Range 17.0-28.0). Both mean age and BMI was significantly higher in SSI+ group than in SSI- group. (Table 2). Incidence of SSI among patients aged more than 40 years was $40.5 \%$ compared to $14.7 \%$ in the younger group $(p<0.001)$. Out of the 192 procedures, $79(41.1 \%)$ were day case surgeries. Local, regional and general anesthesia were used in $77(40.1 \%), 70(36.45 \%)$ and 45 $(23.44 \%)$ cases respectively. All were open procedures as laparoscopy facility was not available. Number of procedures and SSI among each type of procedure is shown in Fig. 1.

The association between potential risk factors and SSI was performed using the chi-square test for discrete variables and independent sample t-test for continuous variables (Table I). Risk factors significantly associated

Table-I

\begin{tabular}{|c|c|c|c|}
\hline \multicolumn{4}{|c|}{ Risk factors related to surgical site infection $(n=192)$} \\
\hline Risk factor & SSI+ group & SSI- group & $\mathrm{p}$ value \\
\hline$\overline{\mathrm{Age}}, \mathrm{mean} \pm \mathrm{SD}$ & $40.77 \pm 8.04$ & $33.05 \pm 8.99$ & $<0.05$ \\
\hline Sex & & & $<0.05$ \\
\hline Male (99) & $22(22.2 \%)$ & $77(77.8 \%)$ & \\
\hline Female (93) & $17(18.3 \%)$ & $76(81.7 \%)$ & \\
\hline $\mathrm{BMI}$, mean $\pm \mathrm{SD}$ & $24.64 \pm 1.67$ & $23.18 \pm 1.94$ & $<0.05$ \\
\hline ASA grade & & & $<0.05$ \\
\hline Grade I(145) & $20(13.8 \%)$ & $125(86.2 \%)$ & \\
\hline Grade II (35) & $15(42.9 \%)$ & $20(57.1 \%)$ & \\
\hline Grade III (12) & $4(33.3 \%)$ & $8(66.7 \%)$ & \\
\hline Wound classification & & & $<0.05$ \\
\hline Clean (183) & $36(19.7 \%)$ & $147(80.3 \%)$ & \\
\hline Clean-contaminated (7) & $1(14.3 \%)$ & $6(85.7 \%)$ & \\
\hline Contaminated/Dirty (2) & $2(100.0 \%)$ & $0(0.0 \%)$ & \\
\hline Diabetes mellitus & & & $<0.05$ \\
\hline Yes (44) & $24(54.5 \%)$ & $20(45.5 \%)$ & \\
\hline No $(148)$ & $15(10.1 \%)$ & $133(89.9 \%)$ & \\
\hline Smoking habit & & & $<0.05$ \\
\hline Yes (58) & $10(17.2 \%)$ & $48(82.8 \%)$ & \\
\hline No (134) & $29(21.6 \%)$ & $105(78.4 \%)$ & \\
\hline Type of surgery & & & $<0.05$ \\
\hline Routine (163) & $29(17.8 \%)$ & $134(82.2 \%)$ & \\
\hline Emergency (29) & $10(34.5 \%)$ & $19(65.5 \%)$ & \\
\hline Duration of surgery, mean \pm SD & $71.15 \pm 33.51$ & $44.48 \pm 17.04$ & $<0.05$ \\
\hline Transfusion & & & $<0.05$ \\
\hline None (157) & $18(11.5 \%)$ & $139(88.5 \%)$ & \\
\hline 1 unit (23) & $13(56.5 \%)$ & $10(43.5 \%)$ & \\
\hline 2 units (10) & $6(60.0 \%)$ & $4(40.0 \%)$ & \\
\hline 3 units (2) & $2(100.0 \%)$ & $0(0.0 \%)$ & \\
\hline
\end{tabular}


with SSI in this study were age, BMI, ASA grade, wound classification, diabetes, type of surgery, duration of surgery and perioperative transfusion $(p<0.05)$. In contrast, risk factors found not to be significantly associated with SSI were sex and smoking.

A logistic regression was performed to analyze the independent effects of age, BMI, ASA category, wound category, duration of surgery, perioperative transfusion, diabetes and type of surgery (Table 3 ). The logistic regression model was statistically significant $\left(\mathrm{c}^{2}=\right.$ $81.409, \mathrm{p}<0.001$ ). The model explained $54.4 \%$ (Nagelkerke $R^{2}$ ) of the variance in SSI and correctly classified $84.9 \%$ of cases. Increasing BMI and longer duration of surgery were positive predictors of SSI, as well as perioperative transfusion. Diabetics were $11.014 \%$ more likely to develop SSI than non-diabetics. SSI was significantly higher after emergency than after routine surgery $(\mathrm{OR}=8.873,95 \% \mathrm{CI}=1.966-40.041)$.

The average length of postoperative hospital stay among the admitted patients $(\mathrm{n}=113)$ was $7.06 \pm 3.57$ days. This was much higher in SSI+ patients $(10.69 \pm$ 3.06) than in SSI- patients $(5.81 \pm 2.81)(p<0.001)$. Secondary wound closure was needed in 27 patients $(27 / 39,69.23 \%)$. Among the 39 SSI patients,

Table-II

Analysis of risk factors for SSI using a multivariate logistic regression model

\begin{tabular}{lcccccc} 
Risk factors & \multicolumn{7}{c}{ Variables in the Equation } \\
\hline & $\mathrm{b}$ & $\mathrm{SE}$ & Wald & Sig. $(p)$ & OR & $95 \%$ CI \\
Age & 0.048 & 0.039 & 1.512 & 0.219 & 1.049 & $0.972-1.132$ \\
BMI & 0.433 & 0.172 & 6.337 & 0.012 & 1.541 & $1.101-2.159$ \\
Duration of surgery & 0.025 & 0.013 & 3.769 & 0.052 & 1.026 & $1.000-1.052$ \\
Periop. Transfusion & 0.840 & 0.442 & 3.617 & 0.057 & 2.316 & $0.975-5.502$ \\
Diabetes mellitus & 2.399 & 0.686 & 12.245 & 0.000 & 11.014 & $2.873-42.222$ \\
Type of surgery & 2.183 & 0.769 & 8.062 & 0.005 & 8.873 & $1.966-40.041$ \\
ASA category & -1.142 & 0.740 & 2.386 & 0.122 & 0.319 & $0.075-1.359$ \\
Wound category & -1.851 & 1.146 & 2.609 & 0.106 & 0.157 & $0.017-1.484$ \\
\hline
\end{tabular}

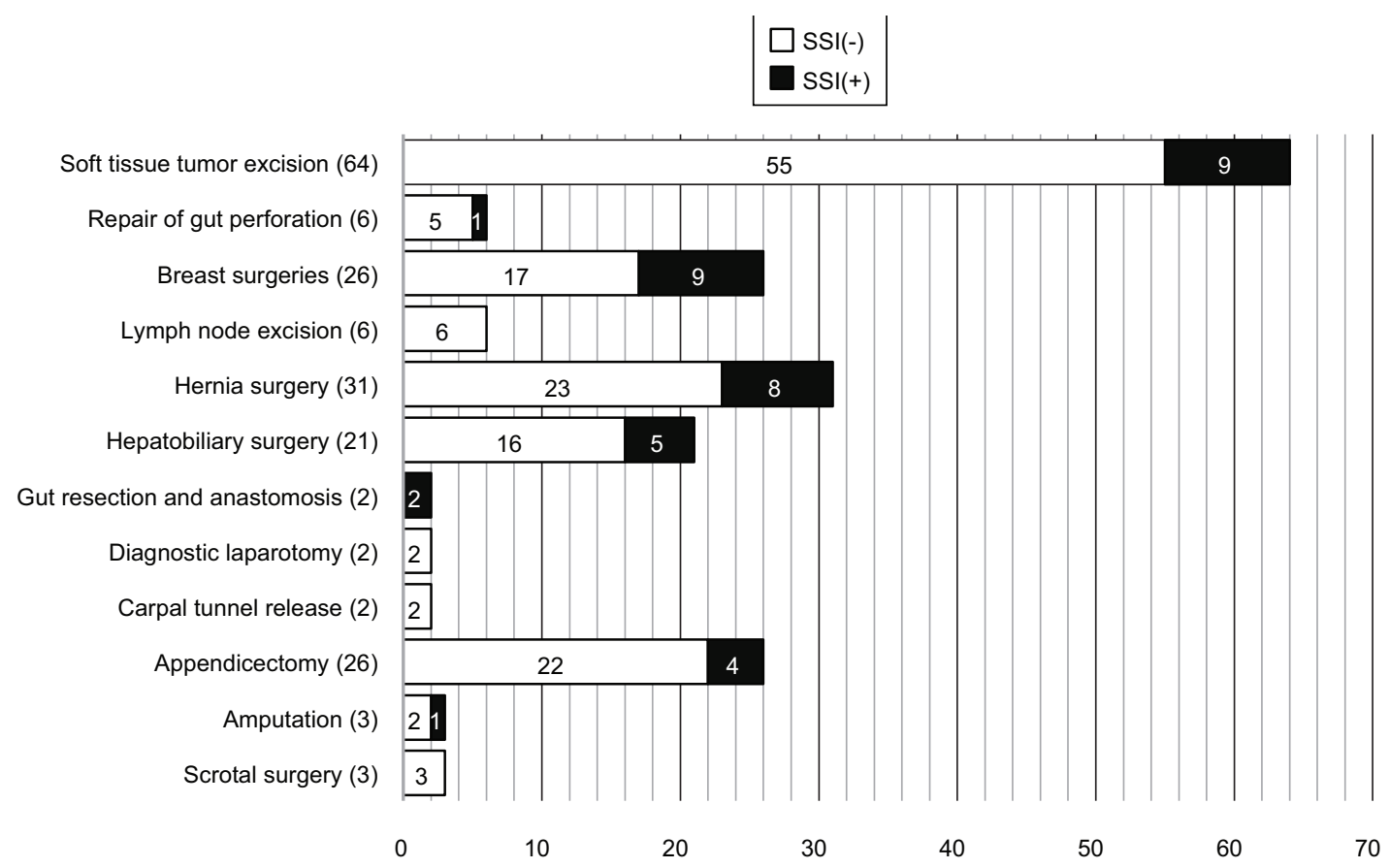

Fig.-1: Types of surgical procedures performed and incidence of SSI in each type ( $n=192)$ 
bacteriological culture was done in only 31 . Commonly cultured organisms include Staphylococcus aureus (41.9\%), Coagulase negative Staphylococci (16.13\%) and E. coli $(16.13 \%)$.

\section{Discussion:}

Surgical site infection, whether superficial involving skin and subcutaneous tissue, or deep involving deeper tissue and/or organ spaces can be a real nuisance and reflects poorly on the surgical team. Considerable effort is given on keeping the rate of SSI as low as possible. Even then it has become an integral part of patient management in a surgical ward. The overall incidence of SSI in this study was $20.31 \%$. Most statistics available in the literature are from the developed countries and much lower than this. The European center for Disease Prevention and Control (ECDC) reported incidence of $0.5-9 \%$ in different procedures. ${ }^{12}$ According to the World Health Organization (WHO) Global Guidelines for the Prevention of Surgical Site Infection, incidence rate of SSI varied remarkable upon countries/regions, surgical procedures performed and also study design.(3) The summarized incidence rates included $0.9 \%$ in the USA (2014), 0.75-9.5\% in European Union (2010-11), 0.4-8.3\% in England (2008-13), 2.8\% in Australia (2002-13), and $15-17.8 \%$ (colorectal surgeries) in Japan (2008-10). Ling et al found that the pooled incidence of SSI in Southeast Asia was 7.8\% (6.3-9.3\%). ${ }^{13}$ A large single center study in Brazil reported 3.4\% SSI incidence over a 4-year period. ${ }^{14}$ The authors themselves suspected lack of post discharge surveillance leading to underreporting of SSI behind this relatively low incidence rate. In India, Tiwari et al found $12.06 \%$ SSI rate in their study conducted in a rural hospital in Maharashtra, while two separate studies in Mumbai reported 9.6\% and 11\% incidence rate respectively. ${ }^{15,16,17}$ Nur-e-Elahi M et al found 20.16\% SSI incidence rate in surgery department of BSMMU, which is almost similar to this study. ${ }^{18}$ In 2018, a comparative study in two tertiary care hospitals in Dhaka reported rates of only $3.0-8.92 \% .{ }^{19}$ Another study conducted in both general surgery and orthopedic ward in a tertiary care center in Barisal found overall prevalence rate of $14.3 \%{ }^{20}$

This study found that advanced age increases the risk of postoperative wound infection. Study done by Patel et al in Gujarat in 2012 showed incidence as high as $36.4 \%$ in age group $>55$ years. ${ }^{21}$ Higher BMI and more diabetics in patients $>40$ years may be the two compounding factors.

Diabetes mellitus is recognized worldwide as a risk factor for development and progression of SSI. Similarly it was an independent risk factor in our study (Table 2). Patients with diabetes are more susceptible due to impaired neutrophil chemotaxis and phagocytosis. ${ }^{22}$ The Gujarat study found $36.4 \%$ SSI rate among diabetics compared to $13.5 \%$ among non-diabetics. ${ }^{21}$ Monjur et al recorded 28 times more chance of SSI in diabetics than in nondiabetics. ${ }^{19}$ In a randomized control trial on adults with complicated appendicitis, diabetes was one of four predictors significantly associated with SSI $(\mathrm{OR}=2.6,95 \% \mathrm{CI}=6.4-11.2) .{ }^{23}$ Another systemic review and meta-analysis conducted by Martin E et al on 94 PubMed indexed articles found diabetes as an independent risk factor for SSI for various types of surgeries $(\mathrm{OR}=1.53) .{ }^{24}$ In this cohort, the association of diabetes with SSI was much stronger $(\mathrm{OR}=11.014,95 \%$ $\mathrm{CI}=2.873-42.222$ ). This may have been compounded by the fact that a substantial number of diabetics had poor glycemic control in the perioperative period.

Higher BMI was another significant independent risk factor in this study. Masoomi $\mathrm{H}$ et al studied 7257 patients who underwent breast reconstruction surgeries during 2011-2015 and found that BMI $>35$ was a significant risk factor for development of wound complication $(\mathrm{OR}=2.38) .{ }^{25}$ Another research conducted on patients undergoing abdominal surgeries found higher BMI to be significantly associated with postoperative wound infections $(\mathrm{OR}=1.2,95 \% \mathrm{CI}=0.68$ 2.1). ${ }^{26}$

ASA grade is an important predictor for development of SSI. The present study cohort had most patients from grade I and II (93.75\%) and none above grade III, as patients with higher ASA grade, requiring major routine surgeries, were referred to tertiary centers for safe anesthetic and postoperative care. As a result, although ASA grade is a recognized risk factor, it was found not to be significant in the regression model.

Carvalho et al found that contaminated and dirty wounds were significantly associated (OR 2.7 and 2.0 respectively) with SSI. ${ }^{14}$ Nolan MB et al observed that current smoking increases the risk of SSI and smoking on the day of surgery is an independent risk factor. ${ }^{27}$ It has also been found that preoperative abstinence from smoking does not 
always reduce the risk of SSI. ${ }^{27}$ But our study found no statistical evidence to suggest as such.

\section{Conclusion:}

This study pointed out risk factors for SSI and its outcome in general surgery patients in a district hospital. The risk factors found significant were consistent with NNIS surveillance guidelines. More comprehensive long term studies with microbiological study should be carried out in outer district hospitals to formulate a standardized protocol for prevention, early identification and better management of SSI.

\section{Conflicts of Interest: None}

\section{Acknowledgement:}

The author would like to thank the Office of the Civil Surgeon, Shariatpur and Superindent, District Hospital, Shariatpur for their kind support and active cooperation in conducting this study. Medical officers working in the ER and OPD also deserve special mention for their help in data collection.

\section{References:}

1. Berriós-Torres SI, Umscheid CA, Bratzler DW, Leas B, Stone EC, Kelz RR, et al. Centers for disease control and prevention guideline for the prevention of surgical site infection, 2017. JAMA Surg. 2017;152(8):784-91. doi:10.1001/jamasurg.2017.0904.https://doi.org/10.1001/ jamasurg.2017.0904.PMid:28467526

2. Onyekwelu I, Yakkanti R, Protzer L, Pinkston CM, Tucker C, Seligson D. Surgical Wound Classification and Surgical Site Infections in the Orthopaedic Patient. JAAOS Glob Res Rev. 2019;1(3):e022. doi: 10.5435/jaaosglobal-d-1700022.https://doi.org/10.5435/JAAOSGlobal-D-1700022.PMid:30211353 PMCid:PMC6132296

3. World Health Organization (WHO). Global guidelines for the prevention of surgical site infection, second edition. Geneva: World Health Organization; 2018. Licence: CC BY-NC-SA 3.0 IGO. Available from https://www.who.int/ publications/i/item/global-guidelines-for-the-prevention-ofsurgical-site-infection-2nd-ed.

4. Allegranzi B, Nejad SB, Combescure C, Graafmans W, Attar $\mathrm{H}$, Donaldson L, et al. Burden of endemic health-careassociated infection in developing countries: systematic review and meta-analysis. The Lancet. 2011 Jan 15;377(9761):228-41https://doi.org/10.1016/S01406736(10)61458-4

5. Mu Y, Edwards JR, Horan TC, Berrios-Torres SI, Fridkin SK. Improving Risk-Adjusted Measures of Surgical Site Infection for the National Healthcare Safely Network. Infection Control \& Hospital Epidemiology. Cambridge
University Press; 2011;32(10):970-86. doi: 10.1086/ 662016. https://doi.org/10.1086/662016.PMid:21931247

6. Saunders L, Perennec-Olivier M, Jarno P, L'Hériteau F, Venier AG, Simon L, et al. Improving prediction of surgical site infection risk with multilevel modeling. PLoS One. 2014;9(5):3-10. doi: 10.1371/journal.pone.0095295., https://doi.org/10.1371/journal.pone. 0095295. PMid: 24835189 PMCid:PMC4023946

7. Marchi M, Pan A, Gagliotti C, Morsillo F, Parenti M, Resi D, Moro ML, the Sorveglianza Nazionale Infezioni in Chirurgia (SNICh) Study Group. The Italian national surgical site infection surveillance programme and its positive impact, 2009 to 2011. Euro Surveill. 2014;19(21):pii=20815.https://doi.org/10.2807/15607917.ES2014.19.21.20815

8. Emori TG, Culver DH, Horan TC, Jarvis WR, White JW, Olson DR, et al. National nosocomial infections surveillance system (NNIS): Description of surveillance methods. Am J Infect Control. 1991 Feb 1;19(1):1935.https://doi.org/10.1016/0196-6553(91)90157-8

9. Birgand G, Lepelletier D, Baron G, Barrett S, Breier AC, Buke C, et al. Agreement among Healthcare Professionals in Ten European Countries in Diagnosing Case-Vignettes of Surgical-Site Infections. PLoS One. 2013;8(7).https:// doi.org/10.1371/journal.pone.0068618. PMid:23874690, PMCid:PMC3706413

10. Horan TC, Andrus M, Dudeck MA. CDC/NHSN surveillance definition of health care-associated infection and criteria for specific types of infections in the acute care setting. Am J Infect Control. 2008 Jun 1;36(5):309-32. https:// doi.org/10.1016/j.ajic.2008.03.002.PMid:18538699

11. Bailey IS, Karran SE, Toyn K, Brough P, Ranaboldo C, Karran SJ. Community surveillance of complications after hernia surgery. BMJ. 1992;304(6825):469-71. https:// doi.org/10.1136/bmj.304.6825.469.PMid:1547415 ,PMCid:PMC1881120

12. European Centre for Disease Prevention and Control (ECDC). Annual epidemiological report for 2016 Healthcare-associated infections: surgical site infections. 2017;(December):7. In: ECDC. Annual epidemiological report for 2016. Stockholm: ECDC; 2018. Available from: https://ecdc.europa.eu/en/publications-data/healthcareassociated-infections-surgical-site-infections-annual-0. [Accessed 8th August, 2019].

13. Ling ML, Apisarnthanarak A, Madriaga G. The burden of healthcare-associated infections in southeast Asia: A systematic literature review and meta-analysis. Clin Infect Dis. 2015;60(11):1690-9.https://doi.org/10.1093/cid/ civ095.PMid:25676799

14. Carvalho RLR, Campos CC, Franco LMC, Rocha AM, Ercole FF. Incidence and risk factors for surgical site infection in general surgeries. Rev Lat Am Enfermagem. 2017;25:e2848. https://doi.org/10.1590/1518-8345. 1502. 2848

15. Tiwari S, Chauhan M, V V S, Akhtar M. J, Grover A, Prashad $S$, et al. Importance of Southampton Wound Grading System in Surgical Site Infection. J Evol Med Dent Sci. 2014;3(20):5491-5.https://doi.org/10.14260/jemds/2014/ 2618 
16. Taori R, Tayade MB. A study of incidence of surgical site infection and associated risk factors at a tertiary care hospital in Mumbai, India. Indian Journal of Research. 2017;6(8):11-14.

17. Akhter MSJ, Verma R, Madhukar KP, Vaishampayan AR, Unadkat PC. Incidence of surgical site infection in postoperative patients at a tertiary care centre in India. $\mathrm{J}$ Wound Care. 2016;25(4):210-7. doi:10.12968/ jowc.2016.25.4.210. https://doi.org/10.12968/jowc.2016. 25.4.210 PMid:27064370

18. Nur-e-elahi M, Jahan I, Siddiqui O, Ahmed S, Joarder A, Faruque S, et al. Wound infection in surgery department in BSMMU: A study of 100 cases. J Bangladesh Soc Anaesthesiol. 2014;24(2):65-9. https://doi.org/10.3329/ jbsa.v24i2.19804

19. Monjur F, Rizwan F, Ghosh NK. Surgical Site Infection Related Risk Factors and Usage of Antibiotics in Two Different Tertiary Care Hospitals of Dhaka City, Bangladesh. Asian J Pharm Clin Res. 2018;11(8):184-88. https://doi.org/10.22159/ajpcr.2018.v11i8.25878

20. Sickder HK, Lertwathanawilat W, Sethabouppha H, Viseskul N. Prevalence of surgical site infection in a tertiary-level hospital in Bangladesh. Int J Nat Soc Sci. 2017;4(3):63-8.

21. Patel S, Patel MH, Patel SD, Soni ST, Kinariwala DM, Vegad MM. Surgical Site Infections: Incidence and Risk Factors in a Tertiary Care Hospital, Western India. Natl J Commun Med. 2012 Jan 1;3:193-6.

22. Cheng K, Li J, Kong Q, Wang C, Ye N, Xia G. Risk factors for surgical site infection in a teaching hospital: A prospective study of 1,138 patients. Patient Prefer
Adherence. 2015 Aug 14;9:1171-7. https://doi.org/10.2147/ PPA.S86153. PMid:26316722, PMCid:PMC4542557

23. Noorit P, Siribumrungwong B, Thakkinstian A. Clinical prediction score for superficial surgical site infection after appendectomy in adults with complicated appendicitis. World J Emerg Surg. 2018;13(1):23-29. https://doi.org/ 10.1186/s $13017-018-0186-1$.PMid:29946346, PMCid:PMC6006790

24. Martin ET, Kaye KS, Knott C, Nguyen H, Santarossa M, Evans R, et al. Diabetes and risk of surgical site infection: A systematic review and meta-analysis. Infect Control Hosp Epidemiol. 2016;37(1):88-99. .https://doi.org/10.1017/ ice.2015.249.PMid:26503187 PMCid:PMC4914132

25. Masoomi H, Fairchild B, Marques ES. Frequency and Predictors of 30-Day Surgical Site Complications in Autologous Breast Reconstruction Surgery. World J Plast Surg. 2019 May;8(2):200-7. https://doi.org/10.29252/ wjps.8.2.200, PMid:31309057, PMCid:PMC6620817

26. Alkaaki A, Al-Radi OO, Khoja A, Alnawawi A, Alnawawi A, Maghrabi A, et al. Surgical site infection following abdominal surgery: A prospective cohort study. Can J Surg. 2019;62(2):111-7. https://doi.org/10.1503/cjs.004818, PMid:30907567, PMCid:PMC6440888

27. Nolan MB, Martin DP, Thompson R, Schroeder DR, Hanson AC, Warner DO. Association Between Smoking Status, Preoperative Exhaled Carbon Monoxide Levels, and Postoperative Surgical Site Infection in Patients Undergoing Elective Surgery. JAMA Surg. 2017 May 1;152(5):476-83. https://doi.org/10.1001/jamasurg. 2016. 5704.PMid:28199450, PMCid:PMC5831446 